\title{
Armazenamento do crambe em diferentes embalagens e ambientes: Parte I - Qualidade fisiológica
}

\author{
Jaqueline F. V. Bessa ${ }^{1}$, Juliana R. Donadon ${ }^{2}$, Osvaldo Resende ${ }^{3}$, \\ Rosa M. V. Alves ${ }^{4}$ Juliana de F. Sales ${ }^{5}$ \& Lílian M. Costa ${ }^{6}$
}

\section{Palavras-chave:}

Crambe abyssinica ambiente refrigerado ambiente natural

\begin{abstract}
R E S U M O
Objetivou-se, neste trabalho, avaliar a qualidade fisiológica das sementes de crambe em diferentes condições de armazenamento, durante nove meses. O crambe com teor de água de 4,63\% base úmida foi acondicionado nas embalagens laminada, polietileno tereftalato (PET) e polietileno de alta densidade (PEAD), as quais foram armazenadas nos ambientes: refrigerado, a $10 \pm 1,19^{\circ} \mathrm{C}$ e $34,84 \pm 4,09 \%$ UR e natural, a $24,81 \pm 1,82^{\circ} \mathrm{C}$ e $54,93 \pm 12,77 \%$ UR. O delineamento utilizado foi o inteiramente casualizado em esquema fatorial triplo (3 $\mathrm{x} 2$ x 4) com três repetições. Os dados foram analisados por meio de análise de variância e regressão. $\mathrm{O}$ ambiente natural e a embalagem PET são os que melhor se apresentam para manter a qualidade fisiológica das sementes de crambe por até seis meses de armazenamento. $\mathrm{O}$ ambiente natural preserva o vigor de sementes e promove superação da dormência primária logo no terceiro mês de armazenamento. $\mathrm{O}$ ambiente refrigerado a $10{ }^{\circ} \mathrm{C}$ não é recomendado para o armazenamento das sementes de crambe.
\end{abstract}

\section{Key words:}

Crambe abyssinica

refrigerated environment

natural environment

\section{Storage of crambe seeds in different containers and environments: Part I - Physiological quality}

\begin{abstract}
A B S T R A C T
The present study aimed to evaluate the physiological quality of seeds of crambe in different storage conditions for nine months. The crambe with moisture content of $4.63 \%$ (wet basis) was placed in the packages laminated, PET and HDPE, which were stored in environments: refrigerated at $10 \pm 1.19^{\circ} \mathrm{C}$ and $34.84 \pm 4.09 \%$ relative humidity $(\mathrm{RH})$ and natural at 24.81 $\pm 1.82^{\circ} \mathrm{C}$ and $54.93 \pm 12.77 \% \mathrm{RH}$. The completely randomized design in triple factorial (3 $\mathrm{x} 2 \mathrm{x} 4$ ) with three replications was used. Data were analysed by analysis of variance and regression. The natural environment and packaging PET containers is best to maintain seed quality of crambe for up to six months of storage. The natural environment preserves the seed vigor and promotes overcome primary dormancy as early as the third month of storage. The refrigerated environment at $10{ }^{\circ} \mathrm{C}$ is not recommended for storage of seeds of crambe.
\end{abstract}

Protocolo 044-2014 - 10/02/2014 • Aprovado em 10/10/2014 • Publicado em 26/01/2015

${ }^{1}$ LPCPV/IF Goiano. Rio Verde, GO. E-mail: jaqueline@agricola.eng.br

${ }^{2}$ UTASP-CCBS/UFMS. Campo Grande, MS. E-mail: julianadonadon@yahoo.com.br (Autora correspondente)

${ }^{3}$ LPCPV/IF Goiano. Rio Verde, GO. E-mail: osvresende@yahoo.com.br

${ }^{4}$ ITAL. Campinas, SP. E-mail: rosa@ital.sp.gov.br

${ }^{5}$ LS/IF Goiano. Rio Verde, GO. E-mail: julianacefetrv@yahoo.com.br

${ }^{6}$ LPCPV/IF Goiano. Rio Verde, GO. E-mail: lmctpg@yahoo.com.br 


\section{INTRODUÇÃo}

A cultura do crambe vem ganhando importância no Brasil devido à sua aptidão para a produção de biodiesel e potencial para semeadura entre os meses de abril a maio caracterizando a safrinha na região centro-oeste. Originário da região quente e seca da Etiópia foi domesticado na região fria e seca do Mediterrâneo encontrando-se relatos que atestam tolerância das plantas a períodos de estresse hídrico (Teixeira et al., 2011).

$\mathrm{O}$ crambe apresenta alta porcentagem de dormência nas sementes recém-colhidas, o que evidencia a necessidade de maiores estudos e melhoramentos genéticos para que seja viável a germinação das sementes, após a colheita. As espécies cujas sementes apresentam dormência representam problemas para a produção de sementes de vez que demonstram dificuldades para a determinação da sua qualidade para a comercialização (Oliva et al., 2012).

O crambe é um fruto que possui alto teor de óleo em sua composição; segundo Rosseto et al. (2012) é possível extrair em média de 38,56\% de óleo dos frutos.

Conforme Harrington (1973) o teor de água ideal para armazenamento de sementes com alto teor de óleo é de $9 \%$ (b.u.) e valores superiores propiciam rápida deterioração dessas sementes. O estudo dos métodos de armazenamento é de grande importância para se conhecer a melhor forma de se armazenar sementes por longo período de tempo sem perder suas características fisiológicas. A qualidade fisiológica da semente está associada diretamente com o seu poder germinativo, ou seja, com a capacidade do embrião iniciar o crescimento e, sob condições ambientais favoráveis, dar origem a uma plântula normal (Tresena et al., 2009).

O tipo de embalagem utilizada no acondicionamento das sementes durante o armazenamento, também assume importância relevante na manutenção da sua viabilidade e vigor pois está diretamente relacionado com a qualidade fisiológica das sementes armazenadas (Baudet, 2003).

A qualidade fisiológica da semente é avaliada rotineiramente pelo teste padrão de germinação que, conduzido em condições ótimas de ambiente, fornece o potencial máximo de germinação estabelecendo o limite para o desempenho do lote, após sua semeadura. Entretanto e em razão de suas limitações, sobretudo quanto à menor sensibilidade para diferenciar a qualidade $\mathrm{e}$ a frequente diferença dos resultados com a emergência das plântulas em campo são necessários, também, os testes de vigor. Nestes, busca-se obter respostas complementares às fornecidas pelo teste de germinação possibilitando a obtenção de informações consistentes (Ohlson et al., 2010).

Com base no exposto, o objetivo nesta pesquisa foi avaliar a qualidade fisiológica das sementes de crambe durante o armazenamento em diferentes embalagens e ambientes identificando a melhor condição para a conservação do produto.

\section{MATERIAL e Métodos}

O experimento foi realizado no Instituto Federal de Educação, Ciência e Tecnologia Goiano - Câmpus Rio Verde (IF Goiano), no Laboratório de Pós-Colheita de Produtos Vegetais, e no Laboratório de Sementes, no período de julho de 2012 a maio de 2013.
Foram utilizadas sementes de crambe (Crambe abyssinica Hochst), cultivadas no município de Jataí - GO, a $17^{\circ} 53^{\prime} 36,31^{\prime \prime}$ de latitude (S) e $51^{\circ} 42^{\prime} 52,25^{\prime \prime}$ de longitude $(\mathrm{O})$.

O crambe foi colhido mecanicamente com teor de água de aproximadamente $10 \%$ (b.u.) e em seguida encaminhado para a realização da limpeza e secagem.

A secagem foi realizada com ar natural e as sementes dispostas em camada de $0,10 \mathrm{~m}$ sob lona plástica ao sol, revolvidas diariamente até que o teor de água atingisse 4,63\% (b.u.), considerado ideal para o armazenamento seguro do produto, Costa et al. (2013). O teor de água foi determinado segundo o método descrito por Brasil (2009) utilizando-se estufa de circulação de ar forçado (Marconi - MA 035) com temperatura constante de $105 \pm 3{ }^{\circ} \mathrm{C}$ por $24 \mathrm{~h}$.

Após a secagem as sementes de crambe foram armazenadas em garrafas de polietileno de alta densidade (PEAD) de 1,0 $\mathrm{L}$, em garrafas reutilizadas de polietileno tereftalato (PET) de 2,0 L; essas embalagens foram higienizadas com água e detergente neutro e em seguida sanitizadas com solução de $200 \mathrm{~mL} \mathrm{~L}^{-1}$ de cloro ativo e em embalagens laminadas de $1,0 \mathrm{~kg}$, com a seguinte especificação: folha de PET + folha de alumínio $(\mathrm{Al})+$ folha de polietileno de baixa densidade (PEBD). As embalagens foram acondicionadas em ambiente refrigerado $(\mathrm{AR})$ a $10^{\circ} \mathrm{C}$ em câmara $\mathrm{BOD}$ e em ambiente natural $(\mathrm{AN})$ a $25^{\circ} \mathrm{C}$.

A temperatura e a umidade relativa (UR) dos ambientes de armazenamento foram monitoradas por meio de um termohigrógrafo, de 15 em $15 \mathrm{~min}$, diariamente, em todo o período de armazenamento e determinadas as médias mensais.

As embalagens foram encaminhadas ao Instituto de Tecnologia de Alimentos (ITAL) para caracterização quanto à barreira ao vapor d’água. As embalagens flexíveis laminadas foram caracterizadas quanto à taxa de permeabilidade ao vapor d'água, segundo a norma ASTM F1249-06 (2006), e as de PET e PEAD em relação à taxa de transmissão ao vapor d'água, $38{ }^{\circ} \mathrm{C} / 90 \%$ UR (ASTM D 4279-95, 1995).

Durante o armazenamento das sementes de crambe nos diferentes ambientes e embalagens, amostras aos 0 , 3, 6 e 9 meses foram retiradas em triplicata e em ao acaso para avaliação do teor de água, condutividade elétrica, porcentagem de germinação $(\% \mathrm{G})$, porcentagem de plântulas normais (\%PN), índice de velocidade de germinação (IVG) e envelhecimento acelerado, no qual as sementes foram submetidas à germinação.

A condutividade elétrica foi determinada segundo o método descrito por Vieira \& Krzyzanowski (1999). Foram contadas e pesadas quatro subamostras de 50 sementes, de cada tratamento. As amostras foram colocadas em recipientes com $75 \mathrm{~mL}$ de água deionizada e mantidas em câmara com temperatura controlada a $25^{\circ} \mathrm{C}$, durante $24 \mathrm{~h}$ período após o qual se efetuou a leitura com condutivímetro digital de bancada, modelo CD 850, marca Instrutherm.

A \%G foi realizada segundo método descrito por Brasil (2009) utilizando, como substrato, papel mata-borrão devidamente umidificado com água destilada equivalente a 2,5 vezes a massa do substrato seco, em germinador Marconi MA 401 , regulado na temperatura de $25 \pm 2{ }^{\circ} \mathrm{C}$. Utilizaram-se 4 subamostras de 25 sementes. Foram consideradas germinadas as sementes que obtiveram a protrusão da radícula. 
A \%PN foi realizada em conjunto com o teste de germinação computando-se, no $7^{\circ}$ DAS (dias após a semeadura), as plântulas que apresentavam as categorias descritas por Brasil (2009) como plântulas normais.

A partir do $2^{\circ}$ dia efetuou-se, diariamente, a contagem das sementes germinadas para se computar o IVG pelo método de Maguire (1962).

O envelhecimento acelerado (EA) foi realizado segundo o método de Marcos Filho (2005) recomendado para sementes de soja cujas sementes de crambe foram colocadas em caixas plásticas tipo "gerbox" possuindo, em seu interior, uma bandeja de tela de aço inoxidável na qual foram distribuídas as sementes formando uma camada única; no interior das caixas "gerbox" se adicionaram $40 \mathrm{~mL}$ de água, mantendo-os a $41{ }^{\circ} \mathrm{C}$ e $100 \%$ de umidade relativa por $72 \mathrm{~h}$ em germinador; depois de envelhecida realizou-se a $\% \mathrm{G}$.

O experimento foi realizado utilizando-se um delineamento inteiramente casualizado em esquema fatorial triplo $(3 \times 2 \times$ 4), sendo três tipos de embalagens (laminada, PET e PEAD), dois ambientes de armazenamento (AR e AN), quatro tempos $(0,3,6$ e 9 meses) e três repetições por tratamento. Os dados foram analisados por meio de análise de variância seguida de regressão e teste de Tukey $\mathrm{p}<0,05$ de significância para as variáveis quantitativas e qualitativas, respectivamente. Para o fator quantitativo os modelos foram selecionados com base na significância da equação, pelo teste F, na significância dos coeficientes de regressão adotando-se o nível de 0,05 e no coeficiente de determinação ( $\mathrm{R}^{2}$ para regressão polinomial).

\section{Resultados e Discussão}

Pelos resultados obtidos de barreira ao vapor d'água das três embalagens utilizadas no armazenamento, verifica-se que a garrafa PET é mais permeável ao vapor d'água $(0,23$ $\mathrm{g}$ água embalagem $\left.{ }^{-1} \mathrm{~d}^{-1}\right)$, seguida pela garrafa PEAD $(0,02 \mathrm{~g}$ água embalagem ${ }^{-1} \mathrm{~d}^{-1}$ ) a $38{ }^{\circ} \mathrm{C} / 90 \%$ UR. A embalagem flexível laminada possui alta barreira ao vapor d'água uma vez que não foi possível determinar sua taxa de permeabilidade ao vapor d'água no equipamento nem nas condições analíticas utilizadas.

Como as garrafas plásticas apresentam volumes distintos, continham quantidades diferentes de crambe. Desta forma, na embalagem PEAD a quantidade de vapor d'água que entrava nesta embalagem por permeação pelo material do corpo da garrafa e/ou pela tampa e/ou pelo sistema de fechamento, era absorvida pela metade de massa de crambe comparada com a garrafa PET.

Na Figura 1 estão apresentadas a umidade relativa do ar (UR) e a temperatura dos ambientes de armazenamento; as médias gerais de temperatura e UR no ambiente refrigerado

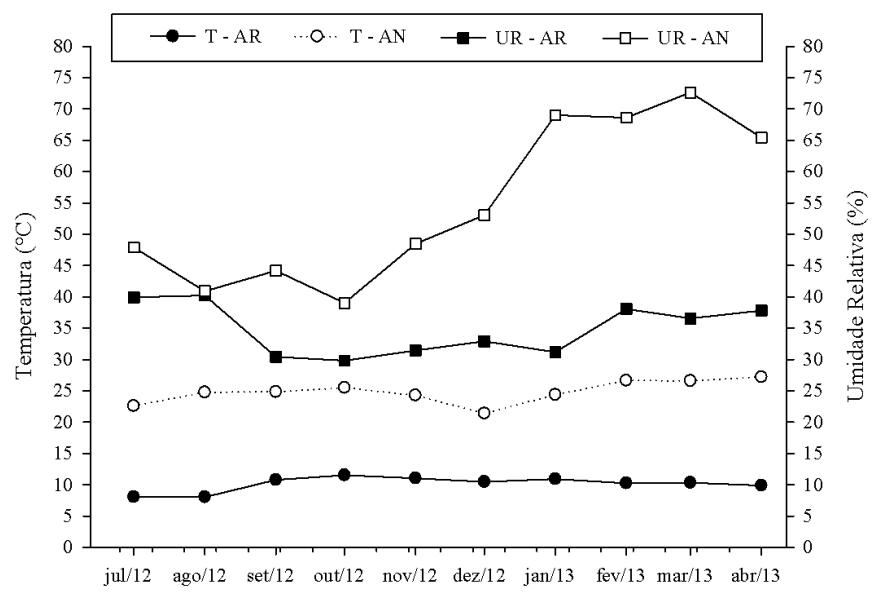

Meses de armazenamento

Figura 1. Médias de temperatura e umidade relativa nos dois ambientes de armazenamento: Refrigerado (AR) e Natural (AN), ao longo dos nove meses

foram de $10,19 \pm 1,19^{\circ} \mathrm{C}$ e de $34,84 \pm 4,09 \%$ e as médias do ambiente natural foram de $24,81 \pm 1,82^{\circ} \mathrm{C}$ e de $54,93 \pm 12,77 \%$, respectivamente.

As condições de umidade relativa e de temperatura durante o armazenamento em que os produtos alcançarão seu equilíbrio higroscópico específico, determinarão a manutenção de sua qualidade fisiológica, por maior ou menor tempo (Borges et al., 2009) razão pela qual é importante armazenar as sementes em embalagens que não permitam trocas com o ambiente de armazenamento.

No AN ocorreu maior variação de temperatura e umidade relativa por influência das condições climáticas visto que a temperatura não foi controlada neste ambiente, porém foi monitorada.

Na Tabela 1 estão apresentadas as médias do teor de água das sementes de crambe, o qual oscilou de acordo com a embalagem, tal como em função das variações da temperatura e da umidade relativa do ar, com valores entre 4,04 e 5,50\% (b.u.) ao longo do armazenamento. Houve interação entre os fatores embalagem $\mathrm{x}$ ambiente $\mathrm{x}$ tempo.

Até o terceiro mês não houve diferença no teor de água das sementes de crambe armazenadas nos dois ambientes. A embalagem $P E T$ proporcionou, às sementes, os maiores níveis de teor de água no AN nos terceiro e sexto meses e no nono mês se destacou com maior teor de água nos dois ambientes de armazenamento em comparação com as demais embalagens.

A embalagem PET apresentou a maior TPVA (taxa de permeabilidade ao vapor d'água) comparada com as demais embalagens, fato que explica a maior oscilação nos valores do teor de água das sementes de crambe ao longo do armazenamento, acondicionadas nesta embalagem. Observa-

Tabela 1. Médias do teor de água (\% b.u.) das sementes de crambe nas diferentes embalagens e ambientes, ao longo do armazenamento

\begin{tabular}{|c|c|c|c|c|c|c|c|c|}
\hline \multirow{3}{*}{ Embs } & \multicolumn{8}{|c|}{ Tempo (meses) } \\
\hline & \multicolumn{2}{|c|}{0} & \multicolumn{2}{|c|}{3} & \multicolumn{2}{|c|}{6} & \multicolumn{2}{|c|}{9} \\
\hline & AR & AN & AR & AN & AR & AN & AR & AN \\
\hline Laminada & $4,63 \mathrm{aA}$ & $4,63 \mathrm{aA}$ & $4,63 \mathrm{aA}$ & $4,62 \mathrm{bA}$ & $4,05 \mathrm{bA}$ & $4,04 \mathrm{bA}$ & 4,27 bA & $4,31 \mathrm{cA}$ \\
\hline PET & $4,63 \mathrm{aA}$ & $4,63 \mathrm{aA}$ & $4,81 \mathrm{aA}$ & $4,91 \mathrm{aA}$ & $4,41 \mathrm{aB}$ & $4,89 \mathrm{aA}$ & $4,47 \mathrm{aB}$ & $5,50 \mathrm{aA}$ \\
\hline PEAD & $4,63 \mathrm{aA}$ & $4,63 \mathrm{aA}$ & $4,74 \mathrm{aA}$ & $4,68 \mathrm{bA}$ & $4,20 \mathrm{bA}$ & $4,16 \mathrm{bA}$ & $4,35 \mathrm{abB}$ & $4,66 \mathrm{bA}$ \\
\hline
\end{tabular}

Embs - Embalagens. PET - polietilefo tereftalato; PEAD - polietileno de alta densidade; AN Ambiente Natural; AR: Ambiente Refrigerado. Letras minúsculas iguais na mesma coluna não diferem entre si. Letras maiúsculas iguais na mesma linha e no mesmo tempo não diferem entre si pelo teste de Tukey $p<0,05$ de significância 
se, na Figura 1, que a UR monitorada no AR apresentou, após o sexto mês de armazenamento, maiores valores em relação ao início do armazenamento ocasionando elevação do teor de água aos nove meses de armazenamento nas sementes acondicionadas em embalagem PET.

Para cada mês de armazenamento ocorreu um aumento de $0,086 \%$ no valor do teor de água das sementes de crambe armazenadas em embalagem PET. Para as embalagens PEAD e laminada, não foi possível ajustar nenhum modelo. Nos dois ambientes as sementes de crambe armazenadas na embalagem PET apresentaram maior teor de água ao longo do armazenamento seguida pelas sementes armazenadas nas embalagens PEAD e laminada, respectivamente.

Quando armazenadas em embalagens permeáveis, as sementes alteram seu teor de água conforme as variações da umidade relativa do ar, por serem higroscópicas. Em embalagens semipermeáveis há alguma resistência às trocas porém insuficiente para impedir completamente a passagem da umidade e em embalagens impermeáveis não há influência da umidade do ar externo sobre as sementes (Baudet, 2003).

Masetto et al. (2013) observaram, armazenando sementes de crambe em embalagens de saco de polietileno e embalagens de plástico rígido em condições ambiente $\left(25 \pm 2{ }^{\circ} \mathrm{C}\right.$ e $\left.60 \% \mathrm{UR}\right)$, câmara fria e seca $\left(15 \pm 2{ }^{\circ} \mathrm{C}\right.$ e $45 \%$ UR) durante 180 dias, valores de teor de água superiores aos do presente trabalho, sendo entre 6,6 e 10,2 \% b.u. e concluíram que a câmara fria e a embalagem de plástico rígido proporcionam a manutenção do vigor das sementes e podem constituir tecnologia eficiente para conservar seu potencial fisiológico, com até 180 dias de armazenamento.

$\mathrm{Na}$ Figura 2 estão apresentados os valores obtidos de condutividade elétrica nas diferentes embalagens e ambientes ao longo do armazenamento.

Ocorreu interação na variável condutividade elétrica entre embalagem $x$ tempo e entre ambiente $x$ tempo. Percebe-se que os valores de condutividade elétrica das sementes armazenadas na embalagem PET apresentaram os menores valores no terceiro e no sexto meses.

Analisando os valores de CE na interação ambiente $x$ tempo, nota-se a diferença dos valores entre as sementes

A.

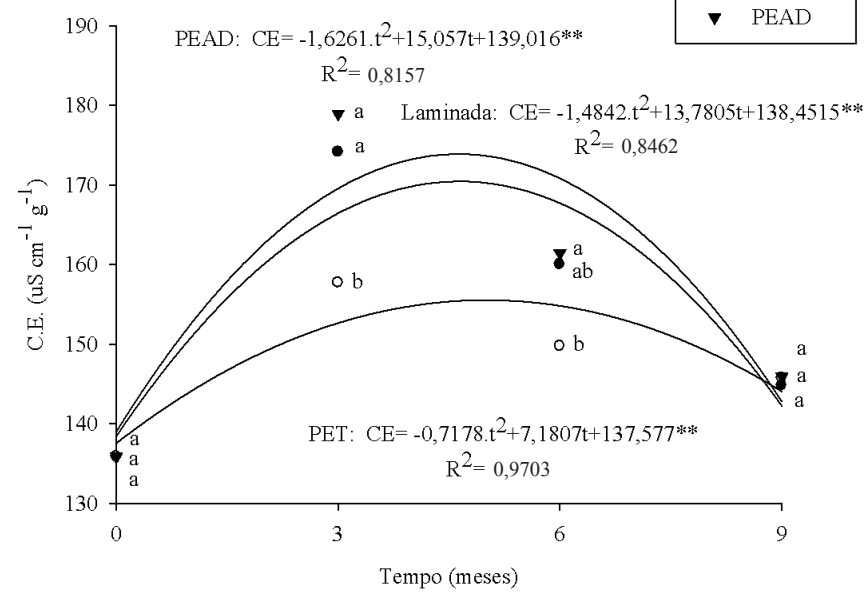

armazenadas nos diferentes ambientes de armazenamento apenas no terceiro mês sendo que as sementes armazenadas no AN apresentaram maiores níveis ao longo do armazenamento.

Costa et al. (2012) obtiveram, avaliando a qualidade das sementes de crambe durante o armazenamento em condições de ambiente $\left(26 \pm 3{ }^{\circ} \mathrm{C} ; 55 \pm 12 \% \mathrm{UR}\right)$, câmara refrigerada (5 $\pm 1{ }^{\circ} \mathrm{C} ; 79 \pm 5 \%$ UR) e câmara climatizada $\left(18 \pm 1{ }^{\circ} \mathrm{C} ; 53 \pm\right.$ $7 \%$ UR), valores acima dos encontrados neste trabalho, entre 291,9 a $443,1 \mu \mathrm{S} \mathrm{cm}^{-1} \mathrm{~g}^{-1}$. As sementes de crambe armazenadas na câmara refrigerada apresentam menores valores de condutividade elétrica em relação às mantidas nas demais condições de armazenamento. Por outro lado, Oliva et al. (2012) encontraram, avaliando o efeito imediato da secagem na qualidade de sementes desta espécie, valores de condutividade elétrica próximos aos da presente pesquisa, entre 122,97 a $144,32 \mu \mathrm{S} \mathrm{cm}^{-1} \mathrm{~g}^{-1}$.

As sementes armazenadas na embalagem PET realizaram maior troca de água durante o armazenamento, fato observado pelas maiores médias de teor de água e a maior TPVA verificada na embalagem PET, o que leva as sementes a absorver facilmente vapor d'água acarretando na desorganização da estrutura da semente e lixiviação de solutos, porém os valores de condutividade elétrica indicam que não houve influência na qualidade fisiológica das sementes de crambe.

Comparando as embalagens e os ambientes ao longo do armazenamento, as sementes de crambe apresentaram baixa lixiviação de eletrólitos e, por consequência, melhor conservação. Os modelos selecionados, tanto para as diferentes embalagens quanto para os diferentes ambientes ao longo do armazenamento, descrevem a variação quadrática da condutividade elétrica.

A CE das sementes armazenadas nas embalagens laminada, PET e PEAD atingiram um ponto de máxima de 170,44; 155,53 e $173,87 \mu \mathrm{S} \mathrm{cm}^{-1} \mathrm{~g}^{-1}$ em 4,64; 5,0 e 4,63 meses de armazenamento, respectivamente; já as sementes armazenadas no AR e AN obtiveram um ponto de máxima $\mathrm{CE}$ de 161,56 e 171,88 $\mu \mathrm{S} \mathrm{cm}^{-1}$ $\mathrm{g}^{-1}$ em 5,11 e 4,46 meses de armazenamento, respectivamente.

$\mathrm{Na}$ Figura 3 estão apresentadas as médias de \%G, \% PN e IVG nas diferentes condições de armazenamento. Houve

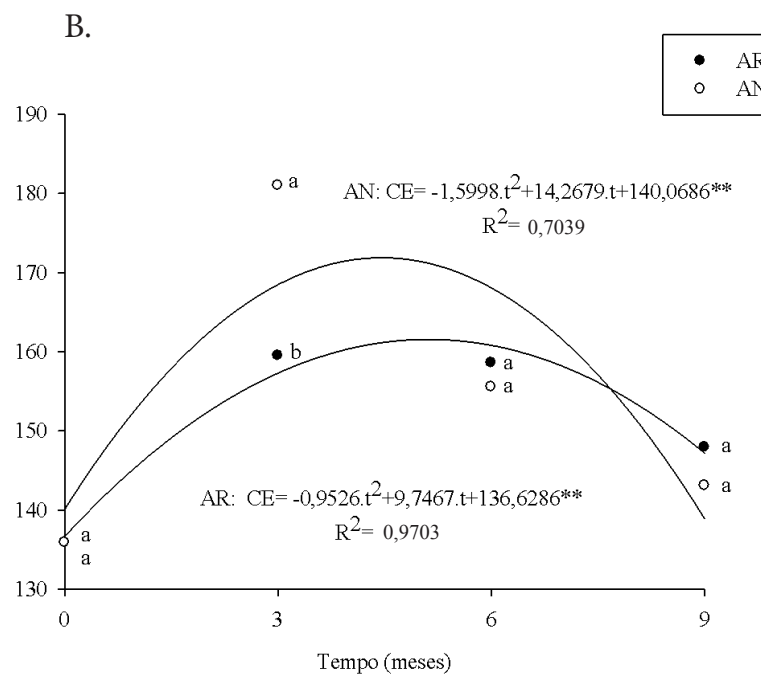

Letras iguais no mesmo tempo não diferem entre si pelo teste de Tukey $p<0,05$ de significância; PET - polietileno tereftalato; PEAD - polietileno de alta densidade; AN - ambiente natural; AR - ambiente refrigerado; ${ }^{*}$ Significativo a $1 \%$

Figura 2. Condutividade elétrica $\left(\mu \mathrm{S} \mathrm{cm}^{-1} \mathrm{~g}^{-1}\right)$ das sementes de crambe nas diferentes embalagens (A) e nos diferentes ambientes (B) em função do tempo 

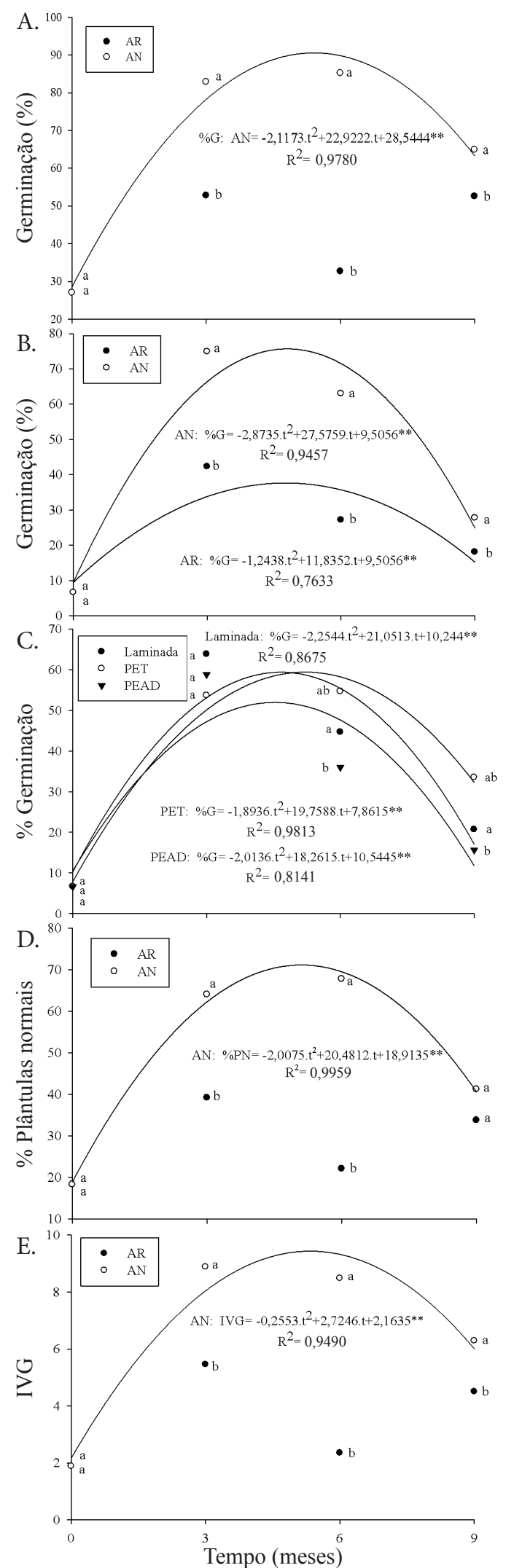

Letras iguais no mesmo tempo não diferem entre si pelo teste de Tukey $p<0,05$ de significância; AN - ambiente natural; AR - ambiente refrigerado; PET - polietileno tereftalato; PEAD - polietileno de alta densidade; ** Significativo a $1 \%$

Figura 3. \%G do crambe nos diferentes ambientes das sementes não envelhecidas ( $A$ ) e das sementes envelhecidas nos diferentes ambientes (B), \%G das sementes envelhecidas nas diferentes embalagens (C), \% PN (plantas normais) das sementes não envelhecidas (D) e índice de velocidade de germinação (IVG) nos diferentes ambientes das sementes não envelhecidas (E) em função do tempo

interação entre o ambiente $\mathrm{x}$ tempo para as variáveis \%G, \%PN, IVG e envelhecimento acelerado, nas sementes de crambe. Existe efeito na interação de embalagem $x$ tempo para a \%G das sementes envelhecidas.

O coeficiente de variação nas avaliações de \%G, \%PN e IVG foi alto devido à oscilação dos valores dessas variáveis pela rusticidade que a cultura apresenta haja vista que o crambe não passou por um processo de seleção nem de melhoramento genético, o que poderia auxiliar na superação da dormência.

No início, foi notória a baixa $\% \mathrm{G}$, ocorrendo aumento ao longo do armazenamento sobremaneira para as sementes armazenadas no AN (Figura $3 \mathrm{~A} \mathrm{e} \mathrm{B).} \mathrm{Isto} \mathrm{mostra} \mathrm{que} \mathrm{as}$ sementes de crambe armazenadas em AN com temperatura média de $25{ }^{\circ} \mathrm{C}$ conseguem superar sua dormência primária ao longo do armazenamento mais rapidamente que aquelas armazenadas no $\mathrm{AR}$ a $10{ }^{\circ} \mathrm{C}$. Ocorreu queda da $\% \mathrm{G}$ após o sexto mês porém o AN comparativamente ao AR se mostrou melhor para a conservação das sementes de crambe, durante nove meses.

O modelo quadrático descreve adequadamente a $\% \mathrm{G}$ das sementes de crambe, exceto no AR da Figura 3B, em que não se ajustou nenhum modelo. Supõe-se que o AR induziu as sementes a uma dormência secundária após a dormência primária ter sido superada no terceiro mês.

Os termos dormência primária e secundária têm sido utilizados para caracterizar os casos em que o fenômeno é induzido durante a maturação e após a colheita, respectivamente. Não há argumento baseado na fisiologia vegetal que permita sustentar esta separação; ambas podem ser superadas pelo mesmo tratamento e se manifestar em resposta às condições adversas do ambiente (Marcos Filho, 2005).

As sementes armazenadas no AN (Figura $3 \mathrm{~A}$ ) obtiveram um ponto de máxima $\% \mathrm{G}$ de $90,58 \%$ aos 5,41 meses de armazenamento. A \%G das sementes envelhecidas (Figura 3B) armazenadas nos AR e AN obtiveram um ponto de máxima de 37,66 e 75,66\% em 4,76 e 4,8 meses de armazenamento, respectivamente. A $\% \mathrm{G}$ das sementes de crambe envelhecidas (Figura 3C) armazenadas nas embalagens laminada, PET e PEAD obtiveram um ponto de máxima de 59,39; 59,4 e $51,95 \%$ em 4,67; 5,22 e 4,53 meses de armazenamento, respectivamente.

Nos dados apresentados por Cruz et al. (2013) que analisaram diferentes testes de vigor para avaliação da qualidade de cinco lotes de sementes de crambe submetidas ao EA, após $24 \mathrm{~h}$ expostas a condições de estresse, a \%PN não apresentou diferença nos lotes $2,3,4$ e 5, comparadas ao controle (sementes não envelhecidas) porém, analisando as Figuras $3 \mathrm{~A}$ e $3 \mathrm{~B}$ do presente trabalho, observa-se a diferença da $\% \mathrm{G}$ das sementes envelhecidas (Figura $3 \mathrm{~A}$ ) e as $\% \mathrm{G}$ das sementes não envelhecidas (Figura 3B), notando que $24 \mathrm{~h}$ de envelhecimento foram suficientes para auxiliar na determinação do melhor ambiente para armazenar as sementes de crambe visto que a $\% \mathrm{G}$ das sementes envelhecidas foi menor.

Considerando a \%G, o AN mostrou-se melhor para armazenar as sementes de crambe por até seis meses, independentemente do tipo de embalagem utilizada. Até o sexto mês as sementes apresentaram porcentagem dentro dos padrões de comercialização de sementes no Brasil, que é de no mínimo $80 \%$. 
A \%G das sementes não envelhecidas armazenadas nos diferentes tipos de ambiente variou de 27,0 a $85,22 \%$ ao longo do armazenamento enquanto a $\% \mathrm{G}$ das sementes envelhecidas foi entre 6,67 e $74,89 \%$. O teste de envelhecimento acelerado ratificou os resultados das sementes não envelhecidas apresentando maior porcentagem de vigor que as armazenadas no AR ao longo do período de armazenamento.

Na Figura 3C observa-se que as sementes armazenadas em embalagem PET apresentaram as maiores médias de \%G diferindo das sementes armazenadas em PEAD no sexto e no nono mês de armazenamento. Silva et al. (2010) também verificaram, avaliando a viabilidade do armazenamento de sementes de arroz, milho e feijão, em embalagem PET, embalagem plástica com espessura de 0,10 mm e embalagens de papel e plástico trançado, maiores porcentagens de germinação nas sementes dessas espécies armazenadas em embalagens PET.

Oliva et al. (2012) constataram, avaliando o efeito da secagem na qualidade de sementes de crambe, baixa $\% \mathrm{G}$ e alta porcentagem de sementes dormentes na avaliação do teste de tetrazólio, entre 83,12 e $88,75 \%$, sinalizando que as sementes de crambe apresentam alto grau de dormência após a colheita, fato também observado por Costa et al. (2012) em testes de germinação.

Costa et al. (2012) observaram, avaliando a porcentagem de germinação de sementes de crambe em três diferentes ambientes de armazenamento: câmara refrigerada $\left(5 \pm 1^{\circ} \mathrm{C}\right)$, câmara climatizada $\left(18 \pm 1^{\circ} \mathrm{C}\right)$ e condição ambiente $(26 \pm 3$ ${ }^{\circ} \mathrm{C}$ ) que o maior potencial germinativo foi encontrado nas sementes armazenadas na câmara climatizada para os doze meses de armazenamento.

As condições não controladas de temperatura e umidade relativa durante o armazenamento, associadas ao alto teor de óleo das sementes de crambe (característico da espécie), resultam na rápida redução da germinação (Cardoso et al., 2012) porém o crambe demonstrou que temperaturas baixas (neste caso $10^{\circ} \mathrm{C}$ ) não são adequadas para seu armazenamento.

Santos \& Rossetto (2013) obtiveram, avaliando testes de vigor em diferentes lotes de sementes de crambe com teor de água de 6,0; 5,3; 5,0 e 6,0\% (b.u.) \%G de 89, 82, 84 e 66\%, respectivamente. Nas pesquisas foram mantidas, após a colheita, as sementes, em embalagem de papel, a $17^{\circ} \mathrm{C}$ e $46 \%$ UR pelo tempo de dois meses antes de iniciarem as avaliações, o que pode ter auxiliado na superação da dormência primária do crambe que ocorre após a colheita. No teste de envelhecimento acelerado a 36 e $48 \mathrm{~h}$, nas temperaturas de 42 e $45^{\circ} \mathrm{C}$ utilizandose solução de $\mathrm{NaCl}$, os quatro lotes avaliados obtiveram maior \% PN nas duas temperaturas após $48 \mathrm{~h}$ de envelhecimento, fato não observado nas sementes que foram submetidas ao teste padrão, sem adição da solução salina.

Werner et al. (2013) avaliaram diferentes tempos de embebição $\left(24,48,72\right.$ e 96 h) e temperatura $\left(41,43\right.$ e $\left.45^{\circ} \mathrm{C}\right)$ e observaram, no teste de envelhecimento acelerado para sementes de crambe que à medida em que se aumentava o tempo de envelhecimento e a temperatura em ambos os lotes, reduzia-se a \%G e o IVG do crambe e concluíram que o teste de envelhecimento acelerado se mostrou eficaz para avaliar o vigor das sementes de crambe. Os autores constataram também que a temperatura de $43^{\circ} \mathrm{C}$ estimulou a germinação das sementes e o IVG. No presente trabalho as sementes ainda apresentavam, embora supostamente, certa dormência que pode ter sido superada com a alta temperatura e umidade relativa que as sementes foram expostas.

Obtiveram-se maiores médias de \%PN (Figura 3D) para as sementes armazenadas no AN no terceiro e sexto meses de armazenamento, tal como na \%G. O modelo quadrático descreve adequadamente a \% PN no AR. A \% PN variou, nos diferentes ambientes de armazenamento, entre: 18,33 e 67,78\%. As sementes armazenadas em AN obtiveram ponto de máxima $\% \mathrm{PN}$ de 71,15\% aos 5,10 meses de armazenamento.

Comparando a \% PN nos dois ambientes de armazenamento, conclui-se que as sementes armazenadas no AN se apresentaram mais vigorosas pois os valores da \% PN foram maiores em relação aos do AR. Percebe-se que houve efeito do ambiente de armazenamento indicando que as sementes de crambe não se adaptam em condições de armazenamento de $10^{\circ} \mathrm{C}$ de vez que, supostamente, esta temperatura não conseguiu superar a dormência inicial das sementes envelhecidas observando-se, portanto baixa \% PN no AR.

Masetto et al. (2009) obtiveram, avaliando diferentes lotes de sementes de crambe, $\mathrm{PN}$ entre 64 e 86,5\%; possibilitando-se que esses autores podem ter utilizado sementes de crambe após a superação da dormência. Neste trabalho referidos valores foram inferiores, entre 18,33 e 67,78\%, indicando que a dormência do crambe interfere na porcentagem das plântulas normais.

Santos \& Rossetto (2013) obtiveram \%PN de crambe de diferentes lotes após o envelhecimento acelerado em $42^{\circ} \mathrm{C}$, por 36 h entre: 52,0 e $73,0 \%$, por 48 h entre: 52,0 e $71,0 \%$ e em $45^{\circ} \mathrm{C}$ por $36 \mathrm{~h}$ entre: 44,0 e $63,0 \%$ e durante $48 \mathrm{~h}$ entre: 2,0 e $30,0 \%$, mostrando que quanto mais tempo as sementes ficam sob estresse menor será o desenvolvimento de plântulas normais.

As sementes armazenadas no AN se destacaram com as maiores magnitudes de IVG (Figura 3E) apresentando maiores médias no terceiro e no sexto meses sendo que nas sementes armazenadas no AR não houve diferença apresentando um ponto de máximo IVG no AN de 9,43 aos 5,34 meses de armazenamento. Para Oliveira et al. (2009), o IVG pode estimar o vigor das sementes comparando diferentes tratamentos e o associando a outros testes de vigor.

$\mathrm{Na}$ avaliação da qualidade das sementes de crambe em três condições de armazenamento, câmara climatizada $\left(18 \pm 1^{\circ} \mathrm{C}\right.$ e $53 \pm 7 \%$ UR), condição ambiente $\left(26 \pm 3^{\circ} \mathrm{C}\right.$ e $55 \pm 12 \%$ UR $)$ e câmara refrigerada do tipo BOD $\left(5 \pm 1^{\circ} \mathrm{C}\right.$ e $79 \pm 5 \%$ UR $)$, Costa et al. (2012) verificaram que a câmara climatizada conserva melhor a qualidade do crambe em relação às demais e que no armazenamento do crambe por doze meses, nos três ambientes analisados, houve superação de dormência das sementes.

$\mathrm{O} A \mathrm{R}$ proporcionou menores teores de água às sementes armazenadas nas diferentes embalagens, o que propicia o armazenamento por longo período das sementes porém as variáveis $\mathrm{CE}, \% \mathrm{G}$ e $\% \mathrm{PN}$ das sementes armazenadas no ambiente natural não envelhecidas apresentaram a mesma tendência, dentre elas com melhores resultados comparado com as sementes armazenadas em ambiente refrigerado, até o sexto mês. O IVG das sementes armazenadas em AR se destacou com maiores índices até o nono mês. Não houve efeito da embalagem nas variáveis $\% \mathrm{G}$ e $\% \mathrm{PN}$.

De acordo com as avaliações de vigor: \% PN, IVG e envelhecimento acelerado, as sementes de crambe armazenadas 
no ambiente natural, independentemente do tipo de embalagem, se apresentaram mais vigorosas.

\section{Conclusões}

1. O ambiente natural e a embalagem PET mantêm a qualidade fisiológica das sementes de crambe, por até seis meses de armazenamento.

2. O ambiente natural preserva o vigor das sementes e promove superação da dormência primária logo no terceiro mês de armazenamento.

3. $\mathrm{O}$ ambiente refrigerado a $10^{\circ} \mathrm{C}$ não é recomendado para o armazenamento das sementes de crambe.

\section{Agradecimentos}

À FAPEG, a CAPES, ao CNPq, à FINEP e ao IF Goiano pelo apoio financeiro, a CARAMURU e ao ITAL pela parceria.

\section{Literatura Citada}

ASTM International. ASTM D 4279-95 (Reapproved 2009): Standard test method for water vapor transmission of shipping containers - constant and cycle methods. Philadelphia: American Society for Testing and Materials, 1995. 3p.

ASTM International. ASTM F 1249 - 06: Standard test methods for water vapor transmission rate through plastic film and sheeting using a modulated infrared sensor. Philadelphia: American Society for Testing and Materials, 2006. 5p.

Baudet, L. Armazenamento de sementes. In: Peske, S. T.; Rosental, M. D.; Rota, G. R. (ed.). Sementes: Fundamentos científicos e tecnológicos. Pelotas: UFPel, 2003. p.369-418.

Borges, S.; Borges, E. E. L.; Corrêa, P. C.; Brune, A.; Equilíbrio higroscópico e viabilidade de sementes de angico-vermelho (Anadenanthera peregrina (L.) Speng) em diferentes condições ambientais de armazenamento. Scientia Forestalis, v.37, p.475481, 2009.

Brasil. Ministério da Agricultura e Reforma Agrária. Secretaria Nacional de defesa Agropecuária. Regras para Análise de Sementes. Brasília: MAPA, 2009. 399p.

Cardoso, R. B.; Binotti, F. F. S.; Cardoso, E. D. Potencial fisiológico de sementes de crambe em função de embalagens e armazenamento. Pesquisa Agropecuária Tropical, v.42, p.272-278, 2012. http:// dx.doi.org/10.1590/S1983-40632012000300006

Costa, L. M.; Resende, O.; Gonçalves, D. N.; Sousa, K. A. Qualidade dos frutos de crambe durante o armazenamento. Revista Brasileira de Sementes, v.34, p.239-301, 2012. http://dx.doi.org/10.1590/ S0101-31222012000200015

Costa, L. M.; Resende, O.; Oliveira; D. E. C. Isotermas de dessorção e calor isostérico dos frutos de crambe. Revista Brasileira de Engenharia Agrícola e Ambiental, v.17, p.412-418, 2013. http:// dx.doi.org/10.1590/S1415-43662013000400009

Cruz, S. M.; Nery, M. C., Rocha, A. S.; Pinho, E. V. R. V.; Andrade, P. C. R.; Dias, D. C. F. S. Vigor tests for evaluation of crambe (Crambe abyssinica Hochst) seed quality. Journal of Seed Science, v.35, p.485-494, 2013. http://dx.doi.org/10.1590/S231715372013000400010
Harrington, J. Packaging seed for storage and shipment. Seed Science \& Technology, Zürich, v.1, p.701-709, 1973.

Maguire, J. D. Speed of germination-aid in selection and evaluation for seedling emergence and vigor. Crop Science, v.2, p.176-177, 1962. http://dx.doi.org/10.2135/cropsci1962.0011183X000200020033x

Marcos Filho, J. Fisiologia de sementes de plantas cultivadas. Piracicaba: FEALQ, v. 12, 2005. 495p.

Masetto, T. E.; Gordin, C. R. B.; Quadros, J. B.; Rezende, R. K. S.; Scalon, S. P. Q. Armazenamento de sementes de Crambe abyssinica Hochst. ex R.E.Fr. em diferentes embalagens e ambientes. Revista Ceres, v.60, p.646-652, 2013. http://dx.doi.org/10.1590/S0034737X2013000500007

Masetto, T. E.; Quadros, J. B.; Moreira, F. H.; Ribeiro, D. M.; Benites Junior, I.; Rezende, R. K. S. Qualidade fisiológica e sanitária de sementes de crambe produzidas no Estado de Mato Grosso do Sul. Revista Brasileira de Oleaginosas e Fibrosas, v.13, p.107113, 2009.

Ohlson, O. C.; Krzyzanowski, F. C.; Caieiro, J. T.; Panobianco, M. Teste de envelhecimento acelerado em sementes de trigo. Revista Brasileira de Sementes, v.32, p.118-124, 2010. http://dx.doi. org/10.1590/S0101-31222010000400013

Oliva, A. C. E.; Biaggioni, M. A. M.; Cavariani, C. Efeito imediato do método de secagem na qualidade de sementes de crambe. Revista Energia na Agricultura, v.27, p.16-30, 2012.

Oliveira, M. T.; Berbet, P. A.; Pereira, R. C.; Vieira, H. D.; Thiébaut, J. T. L.; Carlesso, V. O. Qualidade fisiológica e potencial de armazenamento de sementes de carambola. Revista Brasileira de Sementes, v.31, p.236-244, 2009. http://dx.doi.org/10.1590/ S0101-31222009000200028

Rosseto, R. E.; Santos, R. F.; Bassegio, D.; Secco, D.; Souza, S. N. M.; Chaves, L. I.; Fornasari, C. H. Efeito da secagem na extração de óleos em plantas com potencial energético. Acta Iguazu, v.1, p.69-77, 2012.

Santos, L. A. S.; Rossetto, C. A. V. Testes de vigor em sementes de Crambe abyssinica. Ciência Rural, v.43, p.233-238, 2013. http:// dx.doi.org/10.1590/S0103-84782013000200007

Silva, F. S.; Porto, A. G.; Pascuali, L. C.; Silva, F. T. C. Viabilidade do armazenamento de sementes em diferentes embalagens para pequenas propriedades rurais. Revista de Ciências AgroAmbientais, v.8, p.45-56, 2010.

Teixeira, R. N.; Toledo, M. Z.; Ferreira, G.; Cavariani, C.; Jasper, S. P. Germinação e vigor de sementes de crambe sob estresse hídrico. Irriga, v.16, p.42-51, 2011.

Tresena, N. L.; Mata, M. E. M. R. C.; Duarte, M. E. M.; Moraes, A. M.; Dias, V. S. Qualidade fisiológica da semente de ipê rosa (Tabebuia hepptahylla (Vellozo) Toledo) submetidas à criopreservação. Revista Brasileira de Produtos Agroindustriais, v.11, p.87-93, 2009.

Vieira, R. D.; Krzyzanowski, F. C. Teste de condutividade elétrica. In: Krzyzanowski, F. C; Vieira, R. D.; França Neto, J. B. (ed.). Vigor de sementes: Conceitos e testes. Londrina: ABRATES, 1999.p.1-26.

Werner, E. T.; Lopes, J. C.; Gomes Junior, D.; Luber, J.; Amaral. J. A. T. do. Accelerated aging test to evaluate the quality of crambe (Crambe Abyssinica Hochst - Brassicaceae) seed physiology. Idesia, v.31, p.35-43, 2013. http://dx.doi.org/10.4067/S071834292013000100005 